\title{
Mapeamento geológico costeiro do canal do Palmital, litoral Norte de Santa Catarina
}

\author{
Celso Voos Vieira ${ }^{*}$ \\ Norberto Olmiro Horn Filho ${ }^{* *}$
}

\section{Resumo}

A presente pesquisa tem como objetivo principal realizar o mapeamento geológico costeiro e reconstituir o modelo de evolução paleogeográfica para o setor oriental da folha Garuva (IBGE, 1981), no entorno do canal do Palmital, nordeste do estado de Santa Catarina.Em trabalhos de campo para a identificação dos depósitos previamente fotointerpretados, foram também realizadas coletas de sedimentos para análises em laboratório envolvendo granulometria e matéria orgânica. Posteriormente, com a utilização de ferramentas de Sistema de Informação Geográfica (SIG), os depósitos foram delimitados e mapeados em escala 1:50.000 tendo como base a folha Garuva. Na área de estudo foram reconhecidos três sistemas: sistema cristalino, formado pelas rochas do embasamento; sistema deposicional continental, formado por cinco depósitos com idades desde o Plioceno até o Quaternário; sistema deposicional litorâneo estuarino, constituído por depósitos formados durante o Holoceno. Com base na interdigitação e disposição das camadas dos depósitos, assim como em feições geomorfológicas, foram determinados cinco estágios de evolução paleogeográfica com idades variando desde o Plioceno até o Holoceno.

Palavras-chave: Geologia costeira; canal do Palmital; mapeamento geológico.

* Universidade da Região de Joinville, Departamento de Geografia, Ciências Biológicas e Engenharia Ambiental.

** Professor Dr. do PPGG, Departamento de Geociências - CFH/UFSC (horn@cfh.ufsc.br).

Geosul, Florianópolis, v. 27, n. 54, p 33-54, jul./dez. 2012 
VIEIRA, C.V. \& HORN FILHO, N.O. Mapeamento geológico costeiro do...

Coastal geologic mapping of Palmital channel, littoral North of the Santa Catarina state

\section{Abstract}

The present research has as its main objective to do the coastal geological mapping and to construct the model of paleogeographic evolution for the eastern sector of the Garuva sheet (IBGE, 1981), around of Palmital channel in the northeast of Santa Catarina state. During fieldwork for the identification of the deposits previously identified by aerophotos, sediments had been collected for analyses in laboratory. Subsequently the deposits were delimited with the Geographical Information Systems (GIS) tools and mapped in scale 1:50.000, having the Garuva sheet as a base. In the study area, deposits of three systems were recognized: crystalline system, formed by the basement rocks of the area; continental depositional system, formed by five deposits with Pliocene to Quaternary ages; estuarine coastal depositional system, constituted by three deposits formed in the Holocene. The paleogeographic evolution has five stages determined through geomorphologic features and the layer arrangement of the deposits with ages since the Pliocene to the Holocene.

Key words: Coastal geology; Palmital channel; geological mapping.

\section{Introdução}

O presente artigo é resultado das pesquisas realizadas na dissertação de mestrado intitulada "Mapeamento geológico costeiro e evolução paleogeográfica do setor oriental da folha Garuva, nordeste de Santa Catarina, Brasil", associada ao Programa de Pós-graduação em Geografia, área de concentração Utilização e Conservação de Recursos Naturais, do Centro de Filosofia e Ciências Humanas da Universidade Federal de Santa Catarina (VIEIRA, 2008).

Devido à grande importância da planície costeira para o desenvolvimento dos municípios do setor nordeste de Santa 
VIEIRA, C.V. \& HORN FILHO, N.O. Mapeamento geológico costeiro do...

Catarina, a caracterização dos aspectos do meio físico ao longo do canal do Palmital torna-se essencial para o futuro planejamento de ocupação destas áreas.

Associada aos fatores de planejamento e zoneamento urbano dos municípios ocorre também a necessidade de averiguar e associar as unidades litoestratigráficas de trabalhos desenvolvidos nas áreas adjacentes (MARTIN et al., 1988; HORN FILHO, 1997; SOUZA, 1999, SOUZA et al., 2001; MAZZER \& OLIVEIRA, 2004), visto as divergências existentes nos mapeamentos e quanto aos modelos de evolução na planície costeira da região.

Um dos aspectos geológicos e evolutivos que merece destaque na área de estudo refere-se à interface entre os ambientes fluviais com os ambientes de baixa hidrodinâmica formados pelo sistema estuarino do canal do Palmital.

Por esses motivos, se faz necessária uma abordagem do ângulo específico no qual a Geografia Física e a Geologia analisam e refletem sobre o espaço, de modo a descrever e analisar a interação e integração dos fenômenos (em termos de espaço), onde as sociedades pretéritas e atuais desenvolvem suas atividades de relação com o meio físico.

A área de estudo está localizada na folha SG-22-Z-B-II-1 (MI-2870/1) do mapeamento sistemático do Instituto Brasileiro de Geografia e Estatística (IBGE) em escala 1:50.000, denominada folha Garuva. A área de estudo abrange três municípios do nordeste do estado de Santa Catarina: Garuva, Joinville e São Francisco do Sul. As principais vias de acesso referem-se às rodovias federais BR-101 e BR-376 e à rodovia estadual SC-415. A referida carta articula-se com as folhas Joinville a sul, São Francisco do Sul a leste, São Miguel a oeste e Pedra Branca do Araraquara ao norte. A região de estudo compreende uma área de $365,38 \mathrm{~km}^{2}$ e está situada entre as latitudes $26^{\circ} 00^{\prime}$ e $26^{\circ} 15^{\prime}$ sul e as longitudes $48^{0} 45^{\prime}$ e $48^{0} 52^{\prime} 3^{\prime}$ ' oeste (Figuras 1 e 2 ). 
VIEIRA, C.V. \& HORN FILHO, N.O. Mapeamento geológico costeiro do...

\section{Material e métodos}

A pesquisa foi dividida em cinco etapas que envolveram: levantamentos bibliográfico e cartográfico preliminares, trabalho de gabinete pré-campo, trabalho de campo, análise laboratorial e trabalho de gabinete final.

Foi adotada como folha base para o mapeamento geológico, a folha topográfica do mapeamento sistemático do IBGE (1981) nº SG22-Z-B-II-1, em escala 1:50.000, denominada folha Garuva. Visto que a carta topográfica em escala 1:50.000 não apresentava detalhamento altimétrico compatível com a proposta da pesquisa, foram obtidas bases topográficas digitais complementares, com o objetivo de detalhar a planície costeira em estudo. As cartas topográficas complementares utilizadas possuem escalas de 1:2.000 e 1:10.000 e estão associadas às áreas urbanas de Joinville e Garuva.

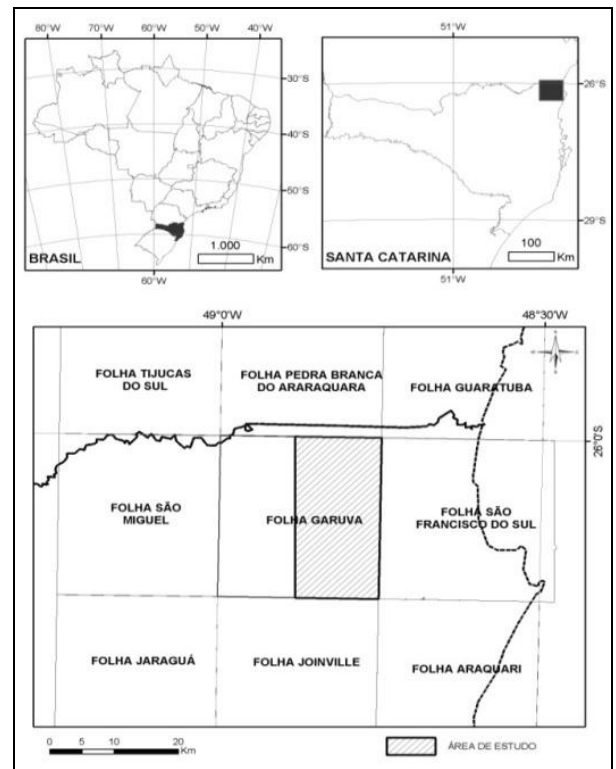

FIGURA 1: Localização da área de estudo no estado de Santa Catarina. 
VIEIRA, C.V. \& HORN FILHO, N.O. Mapeamento geológico costeiro do...

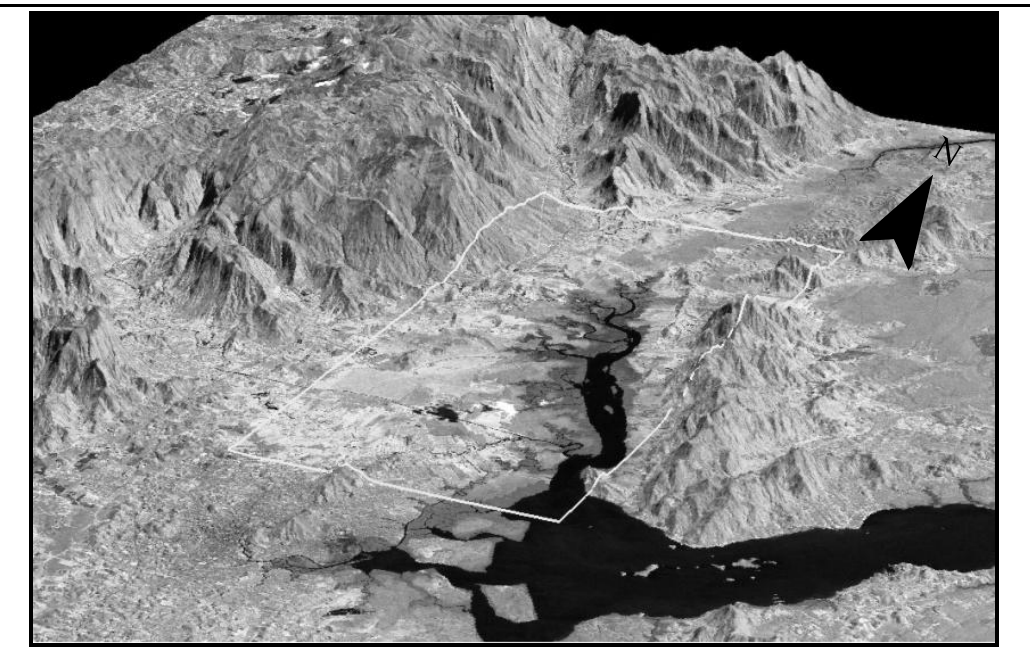

FIGURA 2: Imagem Landsat ETM+ de 02/09/2002, fusão RGB, sobreposta ao Modelo Digital do Terreno (MDT) com destaque para a área de estudo.

Para a fotointerpretação foram empregadas fotos aéreas de diferentes anos em distintas escalas de vôo. As aerofotos adotadas como base para a identificação dos elementos mapeados foram as fotos aéreas datadas de 1975, com escala de vôo de 1:25.000, sendo que as demais aerofotos serviram de complemento para áreas específicas da planície costeira. A resolução espacial das fotos aéreas permitiu a realização de digitalização on screen com grande detalhamento, alcançando escalas até 1:10.000 na identificação e delimitação das feições e depósitos.

O trabalho de campo consistiu na verificação in situ dos depósitos previamente fotointerpretados, de modo a constatar a composição, forma e estrutura dos mesmos. A eleição dos pontos de coleta obedeceu a critérios como: menor perturbação pós-deposicional (antrópica ou natural), acesso a ponto de coleta, representatividade do perfil (número de camadas e profundidade alcançada) e espacialidade dos pontos na área de estudo, contemplando 48 pontos de coleta. 
VIEIRA, C.V. \& HORN FILHO, N.O. Mapeamento geológico costeiro do...

Com objetivo de avaliar a espessura, disposição, composição e estrutura dos depósitos subjacentes foram efetuadas coletas de testemunho com auxílio de testemunhador a percussão.

Para a aquisição da altimetria dos pontos de coleta foi empregado a utilização de receptor GPS com rastreamento de sinal $\mathrm{L}_{1}$ e $\mathrm{L}_{2}$ simultâneo. $\mathrm{O}$ erro associado a este método de coleta foi satisfatório, com um erro médio geral da altimetria de $\pm 8 \mathrm{~cm}$.

Os procedimentos laboratoriais adotados consistem nos métodos clássicos descritos por Bigarella et al. (1955), Reineck \& Singh (1973), Suguio (1973) e Toldo Jr. (1997), entre outras fontes. As análises laboratoriais realizadas compreenderam: análise granulométrica (peneiramento e pipetagem), determinação da porcentagem de matéria orgânica e carbonato biodetrítico. Com base nas análises granulométricas foram realizados análises estatísticas com o auxílio do software Sysgran 3.0 (CAMARGO, 2005), onde foram calculados os parâmetros estatísticos como: diâmetro médio $(\mathrm{Mz})$, desvio padrão $(\mathrm{Dp})$, assimetria $\left(\mathrm{SK}_{\mathrm{i}}\right)$ e curtose $(\mathrm{Kg})$.

\section{Resultados}

De maneira geral a área de estudo tem sua geologia constituída por três sistemas: sistema cristalino, sistema deposicional continental e sistema deposicional litorâneo-estuarino. A figura 3 ilustra os depósitos identificados na área de estudo e o quadro 1 demonstra a área das unidades litoestratigráficas, bem como as porcentagens de ocorrência.

O sistema cristalino ocupa $6,8 \%$ da área considerada, totalizando $23,96 \mathrm{~km}^{2}$. As rochas principais do embasamento consistem de gnaisses, migmatitos, granitos, xistos, cujas idades variam do Arqueano ao Proterozóico.

Os depósitos do sistema deposicional continental representam $260,29 \mathrm{~km}^{2}$ ou $73,3 \%$ da área de estudo. Deste modo, os depósitos deste sistema podem ser classificados como os principais agentes envolvidos na evolução da área estudada, conforme demonstrado no quadro 1. 
VIEIRA, C.V. \& HORN FILHO, N.O. Mapeamento geológico costeiro do...

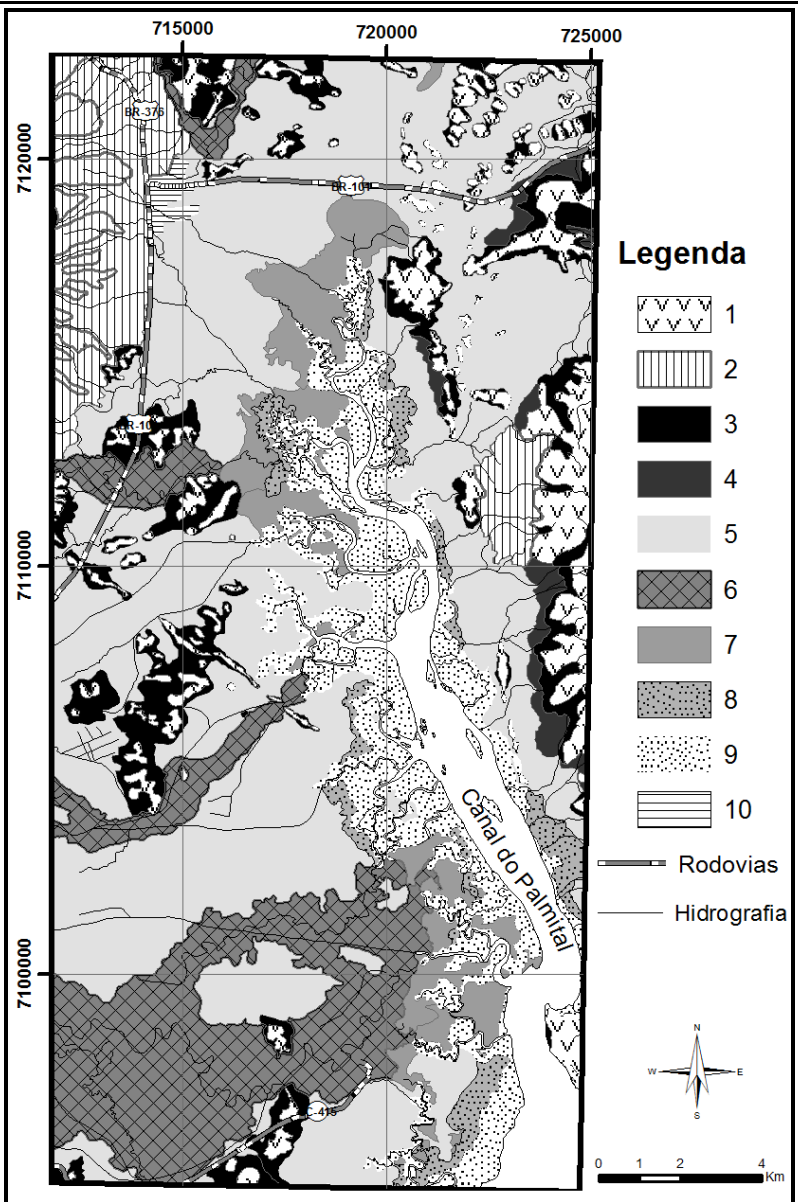

FIGURA 3: Mapa geológico costeiro do canal do Palmital, litoral Norte do estado de Santa Catarina. 1) Embasamento cristalino indiferenciado; 2) Depósito de pedimento (Formação Iquererim). 3) Depósito coluvial. 4) Depósito de leque aluvial proximal. 5) Depósito de leque aluvial distal. 6) Depósito fluvial. 7) Depósito fluvio-estuarino. 8) Depósito paleoestuarino. 9) Depósito paludial estuarino. 10) Área urbanizada. 
VIEIRA, C.V. \& HORN FILHO, N.O. Mapeamento geológico costeiro do...

QUADRO 1: Sistemas e unidades litoestratigráficas.

\begin{tabular}{|c|l|c|c|}
\hline Sistema & \multicolumn{1}{|c|}{ Unidade litoestratigráfica } & \% & Área $\mathbf{( k m}^{\mathbf{2}} \mathbf{~}$ \\
\hline \multirow{2}{*}{$\begin{array}{c}\text { Deposicional } \\
\text { Litorâneo- } \\
\text { Estuarino }\end{array}$} & Depósitos flúvio-estuarinos & 6,1 & 21,32 \\
\cline { 2 - 4 } & Depósitos paleoestuarinos & 2,5 & 8,83 \\
\cline { 2 - 4 } & Depósitos paludiais & 11,3 & 39,98 \\
\hline \multirow{4}{*}{ Deposicional } & Depósitos fluviais & 13,5 & 48,01 \\
\cline { 2 - 4 } & Depósitos aluviais distais & 43,7 & 154,77 \\
\cline { 2 - 4 } & Depósitos aluviais proximais & 1,2 & 4,37 \\
\cline { 2 - 4 } & Depósitos coluviais & 7,7 & 27,45 \\
\cline { 2 - 4 } & Depósitos de pedimento & 7,2 & 25,69 \\
\hline \multirow{2}{*}{ Cristalino } & $\begin{array}{l}\text { Embasamento cristalino } \\
\text { indiferenciado }\end{array}$ & 6,8 & 23,96 \\
\hline \multicolumn{2}{|c|}{ Total } & $\mathbf{1 0 0}$ & $\mathbf{3 5 4 , 3 8}$ \\
\hline
\end{tabular}

Os Depósitos de pedimento correspondem aos depósitos de leques aluviais originados em climas árido ou semi-árido (MAACK, 1947; BIGARELLA et al., 1961; BIGARELLA et al., 1965; MENDES, 1984; ANGULO, 2004). Na área de estudo foi possível reconhecer importantes feições dos leques dos depósitos de pedimentos da Formação Iquererim, com morfologias distinguíveis em dois tipos de leques denominados I e II. Contudo, apesar da distinção morfológica, não foi possível estabelecer nenhuma atribuição/relação cronológica dos mesmos, visto as divergências em torno da idade de formação dos depósitos de pedimentos, com idades estimadas desde o Plio-Quaternário (ANGULO, op.cit.), Quaternário (BIGARELLA et al., 1961, op.cit.) e final do Pleistoceno e início do Holoceno (BESSA JÚNIOR, 1996).

Os depósitos do tipo I localizam-se em situação topográfica mais elevada, nos interflúvios dos cursos d'água que atualmente ocasionam a incisão vertical nos depósitos. De maneira geral, os leques do tipo I possuem maior declividade em relação aos leques do tipo II, assim como menor área. 
VIEIRA, C.V. \& HORN FILHO, N.O. Mapeamento geológico costeiro do...

Os leques de tipo II possuem menores declividades, maior área e são formados por sedimentos erodidos dos leques de tipo I. Desta maneira, em função do maior espraiamento, os leques do tipo II podem alcançar até $4.000 \mathrm{~m}$ de comprimento a partir da linha de ruptura (knick) com a vertente da serra do Mar. Os leques de tipo II nas proximidades do rio São João possuem nítida morfologia de leques ou cones (Figura 4).

A cabeceira dos leques, ou o knick pode ser identificado por uma forte ruptura na declividade das vertentes, onde se inicia o desenvolvimento dos depósitos. O ângulo de ruptura está localizado numa faixa altimétrica que varia entre 300 e $400 \mathrm{~m}$ de altitude, com ângulos variando entre $20^{\circ}$ e $45^{\circ}$. Por vezes, ocorrem depósitos mais recentes recobrindo os depósitos de pedimentos, como depósitos coluviais (tálus), o que ocasiona a suavização do ângulo de ruptura (knick) de contato dos pedimentos com as vertentes da serra do Mar.

A segunda área de ocorrência de Depósitos de pedimento está localizada no setor leste do canal do Palmital, nas proximidades da localidade denominada Barranco. Este depósito possui área menor em relação à Formação Iquererim, visto a disponibilidade de materiais para sua formação. A cota máxima das vertentes da serra associada ao depósito é de aproximadamente $720 \mathrm{~m}$ de altitude e as vertentes da escarpa da serra do Mar possuem altitudes em torno de $1.500 \mathrm{~m}$. A área de ocorrência do Depósito de pedimento foi denominada informalmente de Formação Barranco. Neste depósito a coalescência dos leques formam uma única rampa suavemente inclinada no sentido do canal do Palmital, não sendo identificável a ocorrência de gerações de leques aluviais de morfologias distintas. 
VIEIRA, C.V. \& HORN FILHO, N.O. Mapeamento geológico costeiro do...

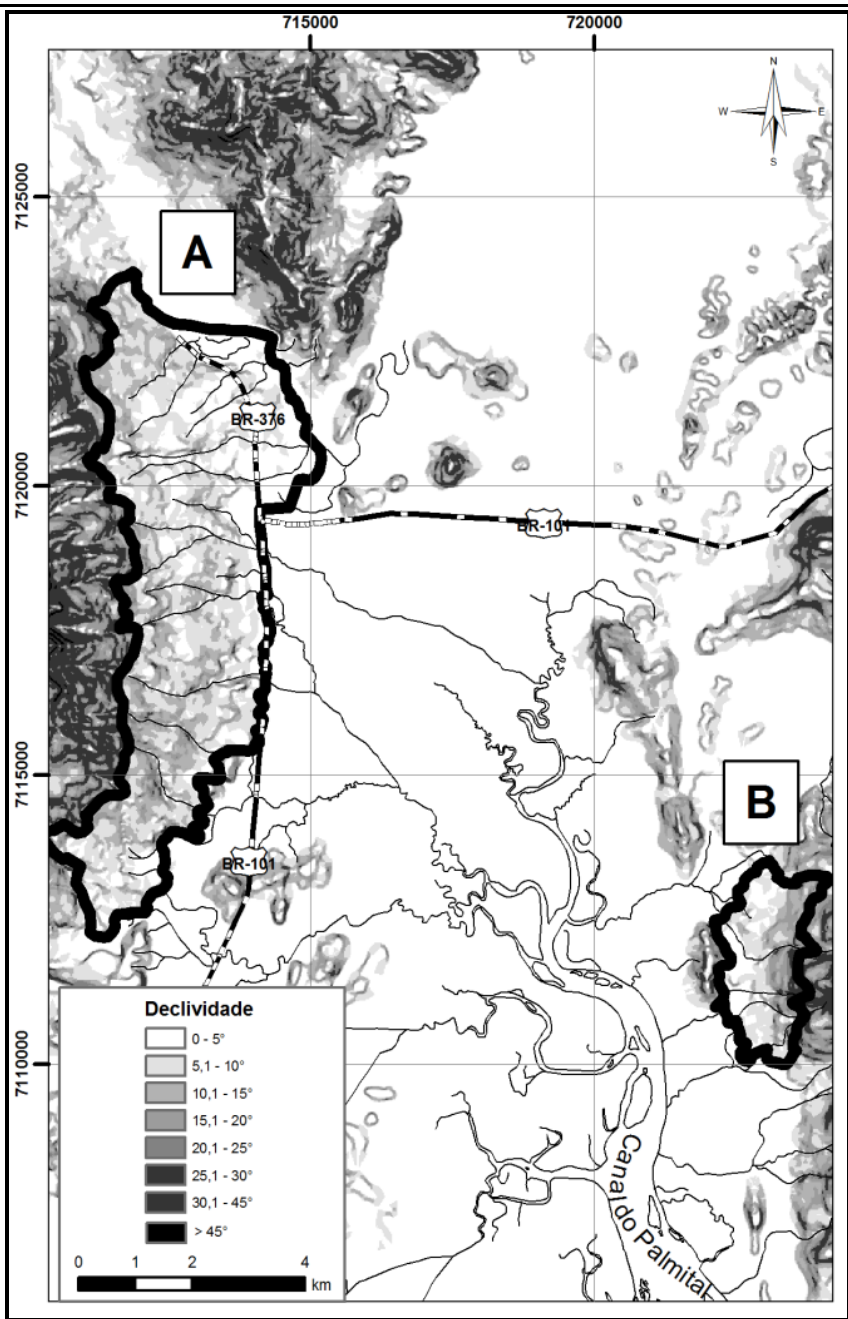

FIGURA 4: Mapa de declividade com destaque para os Depósitos de pedimento. A) Formação Iquererim; B) Formação Barranco.

Com base na proposta de Miall (1985) foi possível identificar a constituição dos Depósitos de pedimento, bem como 
VIEIRA, C.V. \& HORN FILHO, N.O. Mapeamento geológico costeiro do...

os processos associados à sua gênese. Em ambas as ocorrências desses depósitos, os afloramentos podem ser interpretados como depósitos de fluxo de gravidade (SG) - sediment gravity flow deposits. Estes depósitos são formados por processos de fluxo de detritos (debris flow) e apresentam como fácies características aquelas formadas por macroclastos imersos em uma matriz arenoargilosa, sem estruturas visíveis, maciço. A espessura de cada elemento varia de 0,5 a $3 \mathrm{~m}$ e a superfície basal é irregular, mas não erosiva, sendo essa irregularidade proveniente do paleo-relevo.

Os Depósitos coluviais ocorrem em $7,7 \%$ da área, com $27,45 \mathrm{~km}^{2}$. Os setores com maiores ocorrências deste tipo de depósito localizam-se nas vertentes da serra do Mar, sendo ocasionados por processos gravitacionais de caráter dúctil, relacionados aos movimentos de massa translacionais, e por vezes aos fluxos de detritos e lamas (debris flow ou mud flow). Estes processos caracterizam-se pela alta declividade das vertentes e grande extensão do movimento de massa, que ocorrem normalmente no terço superior da vertente. A atividade destes processos pode ser verificada na área de estudo pelas inúmeras cicatrizes de movimentos de massa nas vertentes da serra do Mar. Nas colinas dissecadas da planície costeira ocorrem processos gravitacionais de caráter dúctil (plástico) como o movimento de massa rotacional e solifluxão (creep). Entretanto, também é possível visualizar processos gravitacionais de caráter rúptil (disjuntivo) como a queda de rochas (rockfall).

Quanto aos depósitos aluviais, Galloway \& Hobday (1983), relatam que apesar da desproporcional ênfase dos estudos sobre leques aluviais modernos em regiões áridas, atualmente no registro geológico inúmeros leques formados sob climas úmidos têm sido reconhecidos. Leopold et al. (1964) consideraram que os depósitos de leques aluviais podem ocorrer também em climas úmidos, desenvolvidos pelo escoamento em filetes, em canal e pelo escoamento pluvial. Na área de estudo, os depósitos aluviais compreendem $44,9 \%$ da área total e destacam-se pela homogeneidade morfológica em toda a sua extensão. Os depósitos 
VIEIRA, C.V. \& HORN FILHO, N.O. Mapeamento geológico costeiro do...

aluviais ocorrem em duas situações topográficas distintas: a primeira em áreas de maior declividade associadas às vertentes do embasamento cristalino e aos processos gravitacionais, indicando os setores proximais do depósito; e a segunda, formada por amplas áreas de baixo gradiente clinográfico associadas principalmente a processos de erosão pluvial.

Cabe ressaltar que em toda a extensão da área de estudo os depósitos aluviais distais não apresentam feições associadas a processos fluviais, como canais, meandros abandonados, terraços, ou mesmo depósitos característicos que pudessem indicar uma morfogênese fluvial.

Os Depósitos aluviais proximais são formados por uma interdigitação de incipientes processos fluviais desenvolvidos nas cabeceiras de drenagem e processos gravitacionais situados no terço inferior das vertentes. Os depósitos são heterogêneos, com baixa seleção, constituídos de areia muito fina com presença de grânulos angulosos. Esses depósitos podem ser diferenciados dos depósitos aluviais distais, devido à ausência de processos fluviais e pela alta declividade dos mesmos, associadas exclusivamente a processos gravitacionais.

Os Depósitos aluviais distais ocorrem em altitudes que variam entre 1,9 e $20 \mathrm{~m}$, sendo que as cotas de menor altitude situam-se nas áreas adjacentes ao canal do Palmital. Os depósitos mostram $96 \%$ de sua área com declividades inferiores a $5^{\circ}$, indicando um baixo gradiente clinográfico. Nos depósitos aluviais distais, a curva granulométrica possui tendência muito acentuada aos sedimentos finos, com baixo valor de desvio-padrão, o que indica um contínuo retrabalhamento dos sedimentos a jusante dos depósitos proximais. $\mathrm{Na}$ área de estudo, observa-se uma grande homogeneidade dos Depósitos aluviais distais quanto a sua morfologia, sendo que atualmente o principal processo morfogenético refere-se à ação pluvial direta, com a erosão em lençol (sheet erosion).

Os Depósitos fluviais compreendem uma área de $48,01 \mathrm{~km}^{2} \mathrm{e}$ representam $13,5 \%$ da área de estudo. Os depósitos reconhecidos 
VIEIRA, C.V. \& HORN FILHO, N.O. Mapeamento geológico costeiro do...

estão associados principalmente a quatro bacias hidrográficas, de norte para sul: bacia hidrográfica do Rio São João, bacia hidrográfica do Rio Três Barras, bacia hidrográfica do Rio Pirabeiraba e bacia hidrográfica do Rio Cubatão.

Notadamente, os depósitos fluviais mais expressivos, com ampla planície de inundação na zona costeira, presença de canais e meandros abandonados, assim como inúmeros terraços, estão relacionados aos rios com as vazões mais elevadas da área de estudo. Oliveira (2007) averiguou que nas bacias hidrográficas que compõem a área de estudo, os rios que possuem as vazões médias mais elevadas são os rios Cubatão com $12,14 \mathrm{~m}^{3} / \mathrm{s}$, rio Três Barras $\operatorname{com} 3,53 \mathrm{~m}^{3} / \mathrm{s}$, rio do Braço com $2,14 \mathrm{~m}^{3} / \mathrm{s}$ e rio Pirabeiraba, com $1,96 \mathrm{~m}^{3} / \mathrm{s}$. Todos os demais cursos d'água da vertente oeste do canal do Palmital possuem vazões inferiores a $0,5 \mathrm{~m}^{3} / \mathrm{s}$ (OLIVEIRA, op.cit.). Quanto à morfologia dos canais, os depósitos fluviais podem, grosso modo, ser divididos em três sistemas deposicionais, em função principalmente do tipo de canal (LEOPOLD et al., 1964; MEDEIROS, 1971; MENDES, 1984; SUGUIO \& BIGARELLA, 1990): canal meandrante, canal anastomosado e canal retilíneo. Com relação aos canais meandrantes, praticamente todos os rios da região apresentam este padrão em sua porção mais a jusante, sendo possível identificar dois padrões de bacias hidrográficas, em função do material carreado: pelítico e psamítico. Nos cursos d'água com carga pelítica as fácies constituintes deste sistema são: barras de meandro, diques naturais, depósitos de rompimento de diques e depósitos de planície de inundação. Em geral, na área de estudo os rios com vazão mais elevada e maior área das bacias hidrográficas, possuem canais meandrantes com maior sinuosidade, planície de inundação mais desenvolvida com a presença de inúmeros canais e meandros abandonados e uma predominância no transporte e deposição de material pelítico. Nesta situação, enquadram-se o baixo curso do rio Três Barras, e os canais naturais dos rios Pirabeiraba, Cubatão e do Braço. 
VIEIRA, C.V. \& HORN FILHO, N.O. Mapeamento geológico costeiro do...

Os cursos d'água meandrantes de fáceis psamítica apresentam maior declive, descarga menos uniforme e predominância de carga de fundo. As principais fácies que constituem este sistema são: barras de meandro e barras de corredeira e diques naturais pouco desenvolvidos.

$\mathrm{Na}$ planície de inundação destas bacias hidrográficas não ocorrem vestígios de canais e meandros abandonados, assim como a formação de terraços. Neste quadro incluem-se todos os rios da vertente leste do canal do Palmital e os seguintes rios da vertente oeste: rio Canela, rio Bonito, rio Cupim, rio Sete Voltas e rio da Onça.

Os depósitos do sistema deposicional litorâneo-estuarino representam $70,13 \mathrm{~km}^{2}$ ou $19,8 \%$ da área de estudo. Este sistema deposicional está associado principalmente à influência estuarina nos processos de transporte e deposição dos sedimentos. Os Depósitos paludiais representados pelos atuais manguezais recobrem $11,3 \%$ da área de estudo e destacam-se por ser o ambiente de maior área no sistema deposicional litorâneo. Os Depósitos flúvio-estuarinos e os Depósitos paleoestuarinos possuem área de ocorrência reduzida, no entanto com grande importância para a história geológica evolutiva da área de estudo, com áreas de $6,0 \%$ e $2,5 \%$, respectivamente.

Os Depósitos paludiais, de acordo com Suguio (1998) referem-se a um ambiente de sedimentação próprio de zonas pantanosas periodicamente inundadas por águas salobras. Este ambiente possui ainda, a propriedade de produção de gás sulfídrico $\left(\mathrm{H}_{2} \mathrm{~S}\right)$ e metano $\left(\mathrm{CH}_{4}\right)$, resultando no odor característico destas áreas. Os Depósitos paludiais podem ainda ser enquadrados segundo Reineck \& Singh (1973) como planícies de maré (tidal flats), desenvolvidas ao longo de costas de baixa declividade, com marcado ciclo de marés, ausência de ação de ondas e moderado suprimento de sedimentos.

$\mathrm{Na}$ área de estudo, os Depósitos paludiais foram subdivididos em duas subunidades com base principalmente nos aspectos fitogeomorfológicos: associações arbóreas e associações herbáceas. As associações arbóreas recobrem praticamente toda a 
VIEIRA, C.V. \& HORN FILHO, N.O. Mapeamento geológico costeiro do...

área de planície de maré, sendo a unidade de maior ocorrência. Esta unidade caracteriza-se pela baixa diversidade de espécies, representadas basicamente pela Avicennia schaueriana, Laguncularia racemosa e Rhizophora mangle.

As associações herbáceas são fisionomicamente diferentes em relação aos manguezais, sendo, contudo, encontradas frequentemente associadas a este ecossistema. Estes agrupamentos herbáceos ocorrem próximos aos manguezais, normalmente na forma de: (i) grupos isolados em faixas à frente dos manguezais; (ii) entremeados às espécies arbóreas; (iii) interiorizados em relação aos canais, entre os manguezais e os terrenos mais elevados. No entanto, as áreas mais extensas desta associação ocorrem no extremo norte do canal do Palmital, em locais onde existe importante aporte fluvial, que impede ou dificulta a intrusão salina, onde os manguezais são substituídos pelas associações herbáceas.

Nas áreas mais interiores do complexo estuarino da baía da Babitonga, associados aos Depósitos paludiais, ocorrem áreas de bancos arenosos e areno-argilosos com profundidades inferiores a $2 \mathrm{~m}$. Os bancos normalmente são alongados no sentido da corrente de maré vazante e podem ficar emersos durante as marés mais baixas. A formação dos bancos está associada às zonas de sombra das correntes de maré vazante, pois a mesma possui velocidade mais intensa do que as marés enchente (COPPETEC, 1997; SCHETTINI \& CARVALHO, 1999), o que normalmente ocasiona o prolongamento e desenvolvimento de ilhas a partir de alguma barreira, assim como o desenvolvimento de esporões areno-argilosos formados pelas correntes de maré. Nas áreas menos profundas da baía da Babitonga também podem ser visualizados bancos arenosos e areno-argilosos que constituem feições deposicionais identificadas como deltas de maré vazante (ebb-tidal delta) (ANGULO, 2004). Estas feições associadas à maré vazante (Figura 5) podem ocorrer nas desembocaduras de baías e principalmente na foz dos principais rios que deságuam no canal do Palmital devido à elevada vazão e taxas de transporte de sedimentos.

Os Depósitos paludiais de uma maneira geral podem ser classificados como silte grosso com valor médio de 4,5 phi, muito 
VIEIRA, C.V. \& HORN FILHO, N.O. Mapeamento geológico costeiro do... pobremente selecionado, assimetria positiva e curva granulométrica mesocúrticca. As classes granulométricas indicam $0,4 \%$ de cascalho; $48,7 \%$ de areia e $50,7 \%$ de sedimentos finos (silte + argila). Os pontos com ocorrência de maior quantidade de areia nos depósitos localizam-se na foz dos rios com vazão elevada e altas taxas de transporte de sedimentos como os rios Cubatão, Pirabeiraba e Três Barras.

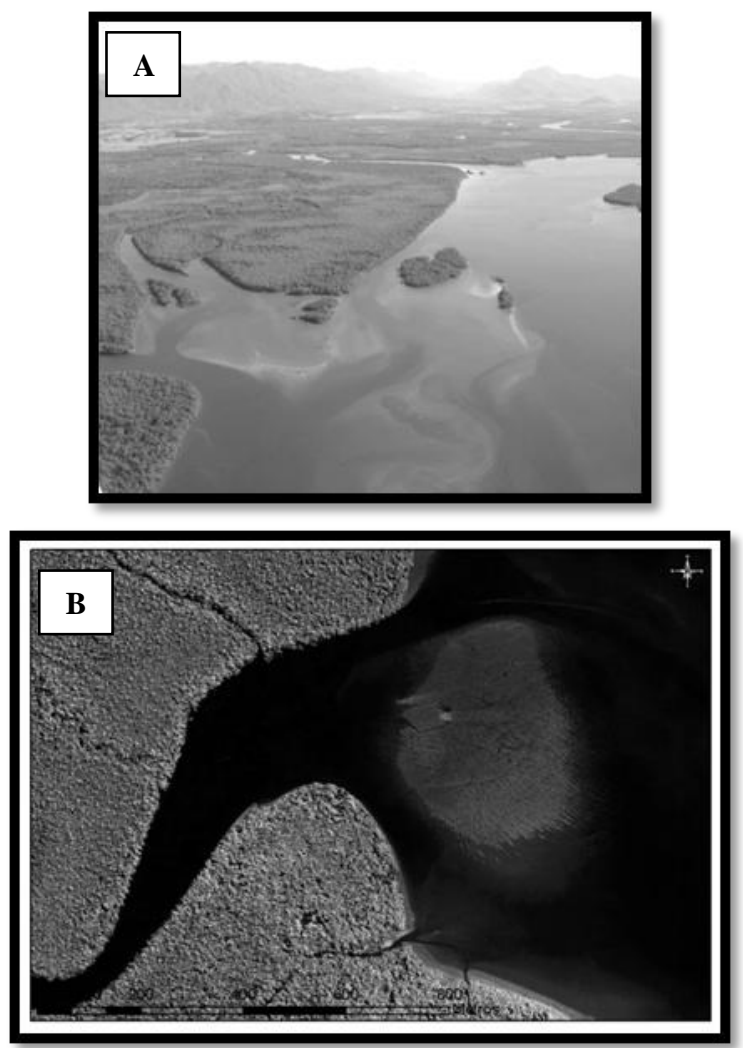

FIGURA 5: Áreas de ocorrência de bancos (A) e deltas de maré vazante (B) do Depósito paludial. 
VIEIRA, C.V. \& HORN FILHO, N.O. Mapeamento geológico costeiro do...

Os Depósitos paleoestuarinos se apresentam na forma de terraços suavemente inclinados em direção ao canal do Palmital, com altitudes inferiores a $2,7 \mathrm{~m}$, sendo que a cobertura vegetal arbórea associada refere-se aos ecossistemas de restinga. Angulo (1992) descreveu que os sedimentos paleoestuarinos podem ser interpretados como depositados em ambiente estuarino ou lagunar. Os sedimentos com estratificação ondulada e bioturbações sugerem ambientes de planície de maré e sedimentos argilo-arenosos com abundantes conchas correspondem à parte inferior da planície de maré ou fundos rasos. Mendes (1984) ressaltou que os depósitos lagunares ou estuarinos formados em nível marinho mais alto que o atual tornam-se de difícil distinção.

De uma maneira geral, os Depósitos paleoestuarinos localizam-se em áreas de baixa influência fluvial, principalmente a leste do canal do Palmital, e a oeste em zonas entre a foz dos rios com vazões elevadas: rio Cubatão, rio Pirabeiraba e rio Três Barras. Os Depósitos paleoestuarinos interdigitam-se com os depósitos aluviais distais, fluviais e flúvio-estuarinos nas áreas mais interiores, e com os depósitos paludiais à frente, nas atuais áreas estuarinas sob influência de maré. Por vezes, verificam-se sucessivos níveis de terraços, principalmente na margem leste do canal do Palmital, que permanecem preservados devido à menor dinâmica fluvial. Normalmente, os níveis de terraços marcam o contato dos Depósitos paleoestuarinos com os depósitos de origem continental. Em vários pontos ao longo dos Depósitos paleoestuarinos podem ser visualizados bancos conchíferos de Anomalocardia brasiliana, compostos por apenas uma das valvas, bastante fragmentadas e arredondadas, o que indica que o banco conchífero estava associado a um banco arenoso ou fundo raso, devido ao intenso sinal de transporte das valvas e da grande extensão do banco conchífero, típico de depósitos estuarinos.

Os Depósitos flúvio-estuarinos podem ser interpretados como o resultado da interação de processos dos ambientes fluvial e estuarino. Os depósitos apresentam-se na forma de terraços suavemente inclinados em direção à foz dos principais cursos 
VIEIRA, C.V. \& HORN FILHO, N.O. Mapeamento geológico costeiro do...

fluviais, com ocorrência de níveis de terraços, canais e meandros abandonados no interior dos depósitos, denotando a influência fluvial na gênese do depósito, sendo que a cobertura vegetal arbórea associada aos depósitos flúvio-estuarinos refere-se aos ecossistemas de restinga. De maneira geral, estes depósitos diferenciam-se dos depósitos paleoestuarinos pela não ocorrência de bancos conchíferos, coloração predominante cinza-escuro, com matéria-orgânica, compostos essencialmente por areia fina, com grânulos esparsos no depósito. Cabe ressaltar que normalmente os depósitos ocorrem sobrepostos aos sedimentos arenosos grossos do fundo do canal do Palmital, evidenciando a progradação de fácies estuarinas sobre depósitos essencialmente marinhos.

\section{Conclusão}

Os depósitos da área de estudo são divididos em um sistema deposicional continental e um sistema deposicional litorâneoestuarino.

O sistema deposicional continental abrange 73,3\% da área de estudo e é constituído por cinco depósitos: Depósitos de pedimento, Depósitos coluviais, Depósitos aluviais proximais, Depósitos aluviais distais e Depósitos fluviais. Os depósitos do sistema deposicional litorâneo-estuarino são representados pelos Depósitos paludiais, Depósitos paleoestuarinos e Depósitos flúvio-estuarinos, formados ao longo do Holoceno e compreendem 19,8\% da área de estudo.

Observa-se que a planície costeira da área de estudo é resultado da progradação de fácies associadas aos depósitos estuarinos e flúvio-estuarinos sobre os depósitos marinhos. A grande disparidade de largura da planície leste e oeste do canal do Palmital estão diretamente associadas à disponibilidade de material para construção fluvial da planície, a partir da serra do Mar. 
VIEIRA, C.V. \& HORN FILHO, N.O. Mapeamento geológico costeiro do...

\section{Referências bibliográficas}

ANGULO, R. J. 1992. Geologia da planície costeira do estado do Paraná. São Paulo. 334p. Tese de doutorado. Programa de Pósgraduação em Geociências. Universidade de São Paulo.

ANGULO, R. J. 2004. Mapa do Cenozóico do litoral do estado do Paraná. Boletim Paranaense de Geociências, 55:25-42.

BESSA JR, O. 1996. Estratigrafia e sedimentação dos depósitos continentais cenozóicos da planície costeira do estado do Paraná. São Paulo. 143p. Dissertação de mestrado. Programa de Pós-graduação em Geociências. Universidade de São Paulo,

BIAS, E. S. 2003. Vantagens e limitações das imagens de alta resolução como suporte ao planejamento urbano: o exemplo de Sobradinho - Distrito Federal. Rio Claro. 280p. Tese de doutorado. Instituto de Geociências e Ciências Exatas. Universidade Estadual Paulista,

BIGARELLA, J. J.; HARTKOPF, C. C.; SOBANSKI, A; TREVISAN, N. 1955. Textura superficial dos grãos em areias e arenitos: contribuição à metodologia. Arquivos de Biologia e Tecnologia, 10, separata.

BIGARELLA, J. J.; MARQUES FILHO, P. L.; AB'SABER, A. N. 1961. Ocorrência de pedimentos remanescentes nas fraldas da serra do Iquererim (Garuva, SC). Boletim Paranaense de Geografia, 4 e 5:83-93.

BIGARELlA, J. J.; MOUSINHO, M. R.; SILVA, J. X. 1965. Pediplanos, pedimentos e seus depósitos correlativos no Brasil. Boletim Paranaense de Geografia, 16 e 17:117-151.

CAMARGO, M. G. 2005. SYSGRAN - Análises e gráficos sedimentológicos. Centro de Estudos do Mar, Universidade 
VIEIRA, C.V. \& HORN FILHO, N.O. Mapeamento geológico costeiro do... Federal do Paraná, versão 3.0. Disponível em http://www.cem.ufpr/sysgran.

COPPETEC, 1997. Estudos hidráulicos e hidrológicos para controle de enchentes na cidade de Joinville. Projeto Joinville Programa de Saneamento Ambiental. Relatório final, 42p.

GAllowAY, W. E. \& HOBDAY, D. K. 1983. Terrigenous clastic depositional system: application to petroleum, coal and uranium exploration. New York: Springer/Verlar, 423p.

HORN FILHO, N. O. 1997. O Quaternário costeiro da ilha de São Francisco do Sul e arredores, nordeste do estado de Santa Catarina - aspectos geológicos, evolutivos e ambientais. Porto Alegre. 283p. Tese de doutorado. Programa de Pós-graduação em Geociências. Universidade Federal do Rio Grande do Sul.

LEOPOLD, L. B.; WOLMAN, M. G.; MILLER, J. P. 1964. Fluvial processes in geomorphology. San Francisco: W. H. Freeman and Company, 522p.

MAACK, R. 1947. Breves notícias sobre a geologia dos estados do Paraná e Santa Catarina. Arquivos de Biologia e Tecnologia, 2: 99-200.

MARTIN, L.; SUGUIO, K.; FLEXOR, J. M.; AZEVEDO, A. E. G. 1988. Mapa geológico do Quaternário costeiro dos estados do Paraná e Santa Catarina. Brasília: DNPM, Série Geologia, n. 28, seção geologia básica, n. 18.

MAZZER, A. M. \& OLIVEIRA, F. A. 2004. Contribuição à geomorfologia da planície costeira da vila da Glória, São Francisco do Sul/SC. Revista da UNIVILLE, 9:37-51.

MEDEIROS, R. A. 1971. Fácies sedimentares: análise e critério para o reconhecimento dos ambientes deposicionais. Rio de Janeiro: CENPES. 
VIEIRA, C.V. \& HORN FILHO, N.O. Mapeamento geológico costeiro do...

MENDES, J. C. 1984. Elementos de Estratigrafia. São Paulo: T. A. Queiroz.

OLIVEIRA, F. A. 2007. Aporte sedimentar em suspensão na baía da Babitonga sob a ótica da geomorfologia. São Paulo. Tese de doutorado. Programa de Pós-graduação em Geografia Física. Universidade de São Paulo.

PINHEIRO, E. S. 2003. Avaliação de imagens Quickbird na análise geográfica de um setor da Mata Atlântica do Rio Grande do Sul. 183p. Dissertação de mestrado. Instituto Nacional de Pesquisas Espaciais.

REINECK, H. E. \& SINGH, I. B. 1973. Depositional sedimentary environments. Berlin, Springer-Verlag, 439p.

SCHETTINI, C. A. F. \& CARVALHO, J. L. B. 1999. Caracterização hidrodinâmica do estuário do rio Cubatão, Joinville. Notas Técnicas FACIMAR, 3:87-97.

SIGA JÚNIOR, O. 1995. Domínios tectônicos do sudeste do Paraná e nordeste de Santa Catarina: geocronologia e evolução crustal. São Paulo. 212p. Tese de doutorado. Programa de Pósgraduação em Geociências. Universidade de São Paulo.

SOUZA, M. C. 1999. Mapeamento da planície costeira e morfologia e dinâmica das praias do município de Itapoá, estado de Santa Catarina: subsídios à ocupação. Curitiba. 196p. Dissertação de mestrado. Programa de Pós-graduação em Geologia. Universidade Federal do Paraná,

SOUZA, M. C.; ANGULO, R. J.; PESSENDA, L. C. R. 2001. Evolução paleogeográfica da planície Costeira de Itapoá, litoral Norte de Santa Catarina. Boletim Paranaense de Geociências, 31(2):223-230. 
VIEIRA, C.V. \& HORN FILHO, N.O. Mapeamento geológico costeiro do...

SUGUIO, K. 1973. Introdução à Sedimentologia. São Paulo: Edgard Blücher, 317p.

SUGUIO, K. 1998. Dicionário de Geologia sedimentar e áreas afins. Rio de Janeiro: Bertrand, 1222p.

SUGUIO, K. \& BIGARELLA, J. J. 1990. Ambiente fluvial. Florianópolis: Editora da UFSC/ Editora da UFPR, 2a ed., 183p.

TOLDO JR, E. 1997. Sedimentologia I e II. Instituto de Geociências, Departamento de Mineralogia e Petrologia, UFRGS, (apostila), 89p.

VIEIRA, C. V. 2008. Mapeamento geológico costeiro e evolução paleogeográfica do setor oriental da folha Garuva, nordeste de Santa Catarina, Brasil. Florianópolis. Dissertação de mestrado. Programa de Pós-graduação em Geografia. Universidade Federal de Santa Catarina.

Recebido em fevereiro de 2012 Aceito em maio de 2012 